\title{
Synthesis and characterization of nanoporous phospho-tungstate organic-inorganic hybrid materials
}

\author{
Katabathini Narasimha Rao, ${ }^{a}$ Lee D. Dingwall, ${ }^{a}$ Pratibha L. Gai,${ }^{a b}$ Adam F. Lee, ${ }^{a}$ \\ Stewart J. Tavener, ${ }^{a}$ Nigel A. Young ${ }^{c}$ and Karen Wilson $* a$
}

\author{
Received 12th October 2007, Accepted 14th December 2007 \\ First published as an Advance Article on the web 16th January 2008 \\ DOI: $10.1039 / b 715826 b$
}

\begin{abstract}
Nanoporous phospho-tungstate organic-inorganic hybrid materials have been synthesized from sodium tungstate and mono- $n$-dodecyl phosphate (MDP), which was used as both surfactant and phosphorus precursor. These hybrid materials were thoroughly characterized by $\mathrm{N}_{2}$ adsorption, elemental analysis, powder XRD, FTIR, Raman, TG, TEM and XPS and possess lamellar structures with interlayer spacings of $3.2 \mathrm{~nm}$. A plausible method for formation of hybrid materials comprised of lacunary Keggin anions and micelles of surfactants is proposed.
\end{abstract}

\section{Introduction}

Inorganic-organic nanocomposite materials have been championed in recent years as potential solutions to various challenges, such as energy supply, storage and production (fuel cells, batteries, solar cells) and information technology. Ideally the partitioning of inorganic and organic species on the nanometre scale should create a homogenous composite possessing advantageous physico-chemical properties with respect to each component. ${ }^{1}$ Considerable effort has been devoted to the design and controlled preparation of such hybrid nanocomposites using colloidal particles as building blocks. A large number of inorganic-core/organicshell hybrids have been fabricated by surface functionalization of metal, metal oxide, and semiconductor nanoparticles, and have been used for a variety of applications ${ }^{2,3,4}$ including catalysis, material science, photo- and electrochemical devices.

Polyoxometalates (POMs) have received much attention owing to their novel compositions, molecular and extended structures and chemical reactivity. ${ }^{5,6}$ POMs can be regarded as extremely versatile inorganic entities for the construction of functionally active solids, and as such constitute nanometre sized building blocks: anions of Keggin derivatives are widely used to generate composite materials. ${ }^{7}$ Muller et $a .^{8}$ have ingeniously synthesized many giant POM clusters, including novel ring and wheel-shaped systems containing as many as $176 \mathrm{Mo}$ atoms. Kurth et al. ${ }^{9}$ and Polarz et al. ${ }^{10}$ have reported the formation of ordered, mesostructured aggregates of molybdenum-based POMs utilising ionic surfactants. Likewise the formation of supramolecular nanostructured materials by complexation of inorganic sandwiched heteropolytungstomolybdate $\mathrm{K}_{13}\left[\mathrm{Eu}\left(\mathrm{SiW}_{9} \mathrm{Mo}_{2} \mathrm{O}_{39}\right)_{2}\right]$ with a cationic surfactant results in materials with strong photoluminescent behaviour. ${ }^{11}$ Neumann et al. ${ }^{12}$ reported the formation of nanoparticle assemblies between POMs and surfactants using caesium

${ }^{a}$ Department of Chemistry, University of York, Heslington, York, UK, YO10 5DD. E-mail: kw13@york.ac.uk; Fax: +44 1904 432516; Tel: +441904432586

${ }^{b}$ York JEOL Nanocentre, University of York, Helix House, Heslington, York, UK, YO10 5BR

'Department of Chemistry, University of Hull, Cottingham Road, Hull, $U K, H U 67 R X$ dodecyl sulfate and Keggin-type POMs such as $\mathrm{H}_{3} \mathrm{PMo}_{12} \mathrm{O}_{40}$ to precipitate spherical composite nanoparticles. Stein et al. ${ }^{13}$ synthesized $\left(\mathrm{C}_{19} \mathrm{H}_{42} \mathrm{~N}\right)_{6}\left(\mathrm{H}_{2} \mathrm{~W}_{12} \mathrm{O}_{40}\right)$ by reacting sodium metatungstate with the surfactant template cetyltrimethylammonium hydroxide. The resulting material contains unconnected Keggin ions $\left[\mathrm{H}_{2} \mathrm{~W}_{12} \mathrm{O}_{40}\right]^{6-}$ packed in a puckered layer arrangement which create roughly spherical cavities for surfactant micelle counterions. Taguchi et al. ${ }^{14}$ have demonstrated the synthesis of super structures constructed from lacunary Keggin anions $\left[\mathrm{PW}_{11} \mathrm{O}_{39}\right]^{7-}$ and dodecyltrimethylammonium cations $\left[\mathrm{CH}_{3}\left(\mathrm{CH}_{2}\right)_{11} \mathrm{~N}\left(\mathrm{CH}_{3}\right)_{3}\right]^{+}$.

Surprisingly there are no reported attempts to synthesise phospho-tungstate organic-inorganic hybrid materials via phosphate based surfactants. The successful application of mono- $n$-dodecyl phosphate, $\mathrm{C}_{12} \mathrm{H}_{25} \mathrm{OPO}(\mathrm{OH})_{2}(\mathrm{MDP})$ as a structure-directing template to prepare mesoporous aluminophosphate/MDP composite materials has been reported by Fröba et al. ${ }^{15}$ This study revealed that the formation of lamellar mesostructured materials did not require $\mathrm{H}_{3} \mathrm{PO}_{4}$ addition as a phosphorus source. Indeed TGA showed the surfactant was more thermally stable following formation of the aluminophosphate, due to incorporation of the phosphate head groups within the inorganic network. In recent research Bose et al. ${ }^{16}$ have also used MDP as a surfactant to prepare nanocrystalline calcium phosphate.

Here we report the first in-situ synthesis of a nanoporous organophospho-tungstate hybrid without recourse to either a POM starting material or extra phosphorus precursor, in which we utilise MDP as both phosphorus source and structural template.

\section{Experimental}

\section{Materials preparation}

Mono- $n$-dodecyl phosphate $\left[\left(\mathrm{C}_{12} \mathrm{H}_{25} \mathrm{O}\right) \mathrm{P}(\mathrm{O})(\mathrm{OH})_{2}, \mathrm{MDP}, 90\right.$ $\mathrm{wt}^{\mathrm{0}} \%$ ] was purchased from Lancaster, UK. Sodium tungstate $\left(\mathrm{Na}_{2} \mathrm{WO}_{4} \cdot 2 \mathrm{H}_{2} \mathrm{O}, 98 \mathrm{wt} \%\right)$ was purchased from Aldrich. Ethanol was purchased from Fisher Scientific. All chemicals were used without further purification. Deionized water and ethanol 30/70 volume ratio was used as a solvent. 
Polyoxometalate hybrid materials were prepared by a simple precipitation method. 0.001 moles of MDP was dissolved in 20 $\mathrm{ml}$ of solvent in a round bottomed flask, followed by the addition of 0.012 moles of sodium tungstate in $10 \mathrm{ml}$ of solvent $(1: 12$ ratio of MDP : sodium tungstate) to yield MDP-POM. The resultant solution was stirred continuously while being maintained at around $\mathrm{pH} 2$ by addition of $0.2 \mathrm{M} \mathrm{HCl}$, and yielded a white precipitate. This precipitate was aged overnight, then filtered and washed with water and acetone three times to remove unreacted sodium tungstate and sodium chloride before drying at $80^{\circ} \mathrm{C}$. Removal of any residual surfactant from the as-synthesised solids was performed by Soxhlet extraction with ethanol containing 10 $\operatorname{vol} \%$ dil. $\mathrm{HCl}(0.1 \mathrm{M})$ for $24 \mathrm{~h}$. The final material was a white powder which was insoluble in polar solvents (inc. ethanol, ethyl acetate, water and acetone). Tungstic acid was prepared under identical conditions, but without addition of MDP.

\section{Characterization}

Nitrogen porosimetry was undertaken on a Micromeritics ASAP 2010 instrument. Surface areas were calculated using a 5-10 point BET plot over the range $P / P_{\mathrm{o}}=0.02-0.2$, where a linear relationship was maintained, while pore size distributions were calculated using the Barrett-Joyner-Halenda (BJH) model up to $P / P_{\mathrm{o}}=0.6$. FTIR spectra were obtained on a Bruker Equinox FTIR spectrometer. Samples were diluted in $\mathrm{KBr}$ prior to analysis. FT-Raman spectra were collected in $180^{\circ}$ scattering geometry from neat samples using a Bruker FRA106/S Raman module mounted on a Bruker Equinox 55 FTIR bench with a cw Nd-YAG $1064 \mathrm{~nm}$ laser operating at 100-400 mW, a $\mathrm{CaF}_{2}$ beam splitter and liquid nitrogen cooled $\mathrm{Ge}$ detector.

Powder X-ray diffraction patterns were collected on a Bruker D8 diffractometer using $\mathrm{Cu} \mathrm{K}_{\alpha}$ radiation. Elemental analysis was conducted on Hitachi atomic absorption spectrometer, while $\mathrm{CHN}$ analysis was performed by the Microanalytical Laboratory at the University of Manchester. XPS was performed with a Kratos AXIS HSi instrument equipped with a charge neutraliser and $\mathrm{Al} \mathrm{K} \mathrm{K}_{\alpha} \mathrm{X}$-ray source. Spectra were recorded at normal emission with an analyser pass energy of $40 \mathrm{eV}$ and $\mathrm{X}$-ray power of $225 \mathrm{~W}$. Binding energies were referenced to both adventitious carbon and the valence band. Spectra were Shirley backgroundsubtracted across the energy region and fitted using CasaXPS Version 2.1.9. ${ }^{31} \mathrm{P}$ MAS NMR spectra were obtained in single pulse (' $Z \mathrm{G}$ ') mode (3.5 ms pulse, and $8 \mathrm{~s}$ delay between pulses) on a Bruker Advance 400 spectrometer, operating at a frequency of 161.98 MHz. NMR measurements were performed in $4 \mathrm{~mm}$ O.D. rotors, with a sample spin rate of $10 \mathrm{kHz}$. Spectra were referenced externally to sodium dihydrogen phosphate $(0.0 \mathrm{ppm})$. Line broadening of $10 \mathrm{~Hz}$ was applied when processing the spectra.

Thermogravimetric analysis was performed using a Stanton Redcroft STA 780 thermal analyzer. The samples were mounted in an alumina crucible and heated at $10{ }^{\circ} \mathrm{C} \mathrm{min}^{-1}$ to $1000{ }^{\circ} \mathrm{C}$

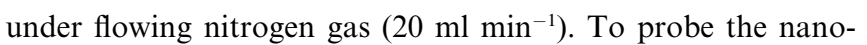
structure, a JEOL 2010 high resolution transmission electron microscope (TEM) operating at $200 \mathrm{kV}$ was used in the JEOL Nanocentre at the University of York. Samples were supported on holey-carbon filmed copper grids. Nanoscale chemical composition analyses were carried out simultaneously by electronstimulated energy dispersive X-ray spectroscopy (EDX) in the electron microscope. For compositional studies, analyses were recorded from several dozen crystals in the sample.

\section{Results and discussion}

The surface and bulk composition of the POM material was first determined by elemental analysis and XPS (Table 1). The bulk chemical composition of MDP is in excellent agreement with the theoretical formula of the template. The surface composition from XPS analysis shows the compositon to be $\mathrm{P}$ and $\mathrm{O}$ enriched, suggesting that MDP orients itself with the hydrophillic phosphate headgroups pointing outwards. Retention of the MDP component following reaction with sodium tungstate to construct the hybrid material MDP-POM is confirmed from the observed $13: 1: 2 \mathrm{C}: \mathrm{P}: \mathrm{W}$ bulk ratio. The slight excess in $\mathrm{C}$ content may be attributed to included solvent following the extraction process. The observed surface $\mathrm{W}: \mathrm{P}$ ratio of $1: 1$, suggests the hybrid material is surfactant terminated with $\mathrm{WO}_{x}$ species occluded in the bulk of the structure.

Thermogravimetric profiles (under nitrogen) for MDP-POM are shown in Fig. 1. Two exothermic weight losses are observed

Table 1 Elemental composition of polyoxometallate hybrid material

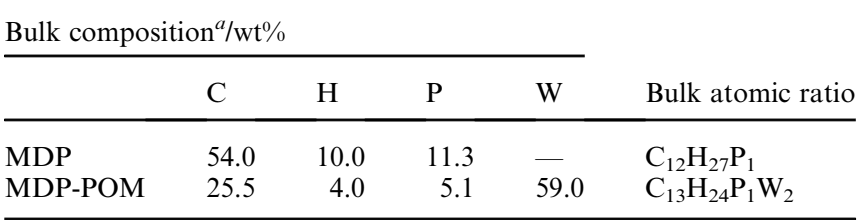

Surface composition ${ }^{b} / \mathrm{wt} \%$

\begin{tabular}{|c|c|c|c|c|c|}
\hline & $\mathrm{C}$ & $\mathrm{O}$ & $\mathrm{P}$ & $\mathrm{W}$ & Surface atomic ratio \\
\hline MDP & 52.9 & 33.0 & 14.1 & - & $\mathrm{C}_{9.7} \mathrm{P}_{1} \mathrm{O}_{4.5}$ \\
\hline MDP-POM & 28.4 & 17.9 & 7.6 & 46.1 & $\mathrm{C}_{9.6} \mathrm{P}_{1} \mathrm{~W}_{1} \mathrm{O}_{4.5}$ \\
\hline
\end{tabular}

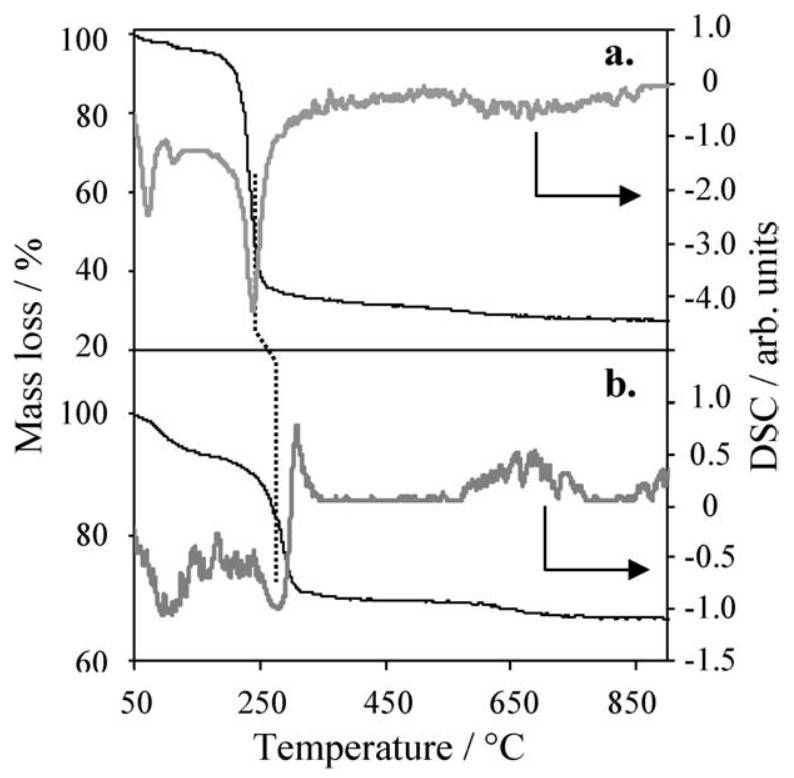

Fig. 1 TGA and DSC measurements on (a) MDP and (b) MDP-POM hybrid samples. 
for the MDP sample at $\sim 120$ and $230^{\circ} \mathrm{C}$, which are attributed to loss of water and decomposition of the MDP hydrocarbon tail. The total loss of $\sim 70 \mathrm{wt} \%$ by $500{ }^{\circ} \mathrm{C}$ is in agreement with the thermal stability of MDP reported by Ying et al. ${ }^{17}$ For the MDP-POM hybrid, the major weight loss occurs at $285{ }^{\circ} \mathrm{C}$, with a total weight loss of $\sim 30 \mathrm{wt} \%$ by $500{ }^{\circ} \mathrm{C}$, consistent with the hydrocarbon content determined by elemental analysis. The increased thermal stability of MDP-POM upon $\mathrm{WO}_{x}$ incorporation suggests a direct interaction between the MDP and tungstate clusters, possibly via the phosphate head group coordinating with the $\mathrm{WO}_{x}$ framework.

The calorimetry measurements reveal this decomposition is coupled with an endothermic process, most likely associated with restructuring of the POM layer upon loss of the hydrocarbon tail. Further heating above $650{ }^{\circ} \mathrm{C}$ results in an additional endothermic weight loss which most likely represents decomposition of the $\mathrm{P}-\mathrm{O}-\mathrm{W}$ framework as observed for phosphotungstic acid. The powder XRD patterns of MDP and MDP-POM are shown in Fig. 2. The ordered lamella structure of the MDP template is evident from the sharp reflections visible at $3.4^{\circ}$, $6.8^{\circ}$ and $10^{\circ}$ corresponding to the (100), (200) and (300) reflections. Following reaction of MDP with the tungstate precursor a new set of peaks are observed at $2.2^{\circ}$ and $4.4^{\circ}$ which are attributed to the (100) and (200) reflections of the composite material, suggesting expansion of the inter-lamellar spacing. The observed diffraction pattern is similar to that observed by Fröba et al. for lamella aluminophosphates prepared with a dodecylphosphate template. ${ }^{15}$ The calculated $d_{(100)}$-spacings of the two samples are presented in Table 2. The wide angle XRD pattern of MDP-POM shown inset also reveals broad diffraction peaks at $2 \theta=8.6^{\circ}, 10.7^{\circ}$ and $12.9^{\circ}$, which may be attributed to polyoxometallate species. For cubic POM materials, the most sensitive region lies between $2 \theta=8^{\circ}$ to $10^{\circ}$ (around the (110) plane), while protonated heteropolyacids give rise to a sharp diffraction peak at $8.2^{\circ}$. The precise $d$ spacings in the unit cell are, however, sensitive to changes in the POM secondary structure originating from inclusion of organic or inorganic species in interstitial sites.

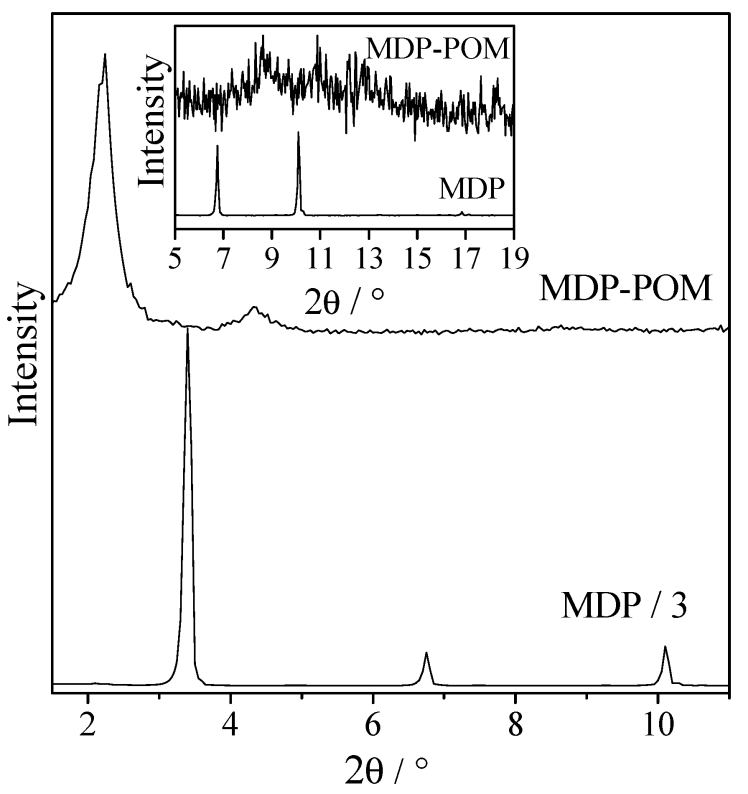

Fig. 2 Powder XRD of MDP and MDP-POM materials.
Table 2 Structural parameters of MDP-POM hybrid materials

\begin{tabular}{lllll}
\hline Material & $\begin{array}{l}\text { Measured } \\
d_{(100)} \text { spacing/nm }\end{array}$ & $\begin{array}{l}\text { Surface } \\
\text { area } / \mathrm{m}^{2} \mathrm{~g}^{-1}\end{array}$ & $\begin{array}{l}\text { Pore } \\
\text { diameter/nm }\end{array}$ & $\begin{array}{l}\text { Wall } \\
\text { thickness } / \mathrm{nm}\end{array}$ \\
\hline MDP & 2.8 & 2 & - & \\
MDP-POM & $4.5^{a}(3.2)^{b}$ & 22 & 3.5 & $0.25-0.5$ \\
${ }^{a}$ Calculated from XRD. ${ }^{b}$ Measured from TEM. & \\
\hline
\end{tabular}

The specific surface areas and pore diameters of these materials are also reported in Table 2. The high order of the MDP results in its low surface area. In contrast the hybrid MDPPOM material exhibited a relatively high surface area of $22 \mathrm{~m}^{2}$ $\mathrm{g}^{-1}$, presumably associated with the reduced crystallite size and associated greater surface area to volume.

The microscopic nature of the hybrid sample was further explored by TEM (Fig. 3a), revealing the presence of large particles up to $120 \mathrm{~nm}$ that apparently result from aggregation of tungstate units. Higher magnification images show the presence of regularly spaced parallel layers (Fig. 3 b) with separations $\sim 3.2$ $\mathrm{nm}$, and also reveal stacking defects. Many of these layers propagate throughout individual particles in an onion-skin structure, terminating at their surfaces. EDAX measurements (inset) confirm the presence of $\mathrm{W}$ in dark regions only. The thickness of these $\mathrm{WO}_{x}$ containing walls is $\sim 1.1 \mathrm{~nm}$. The formation of lamella phases of tungsten oxide has been reported using
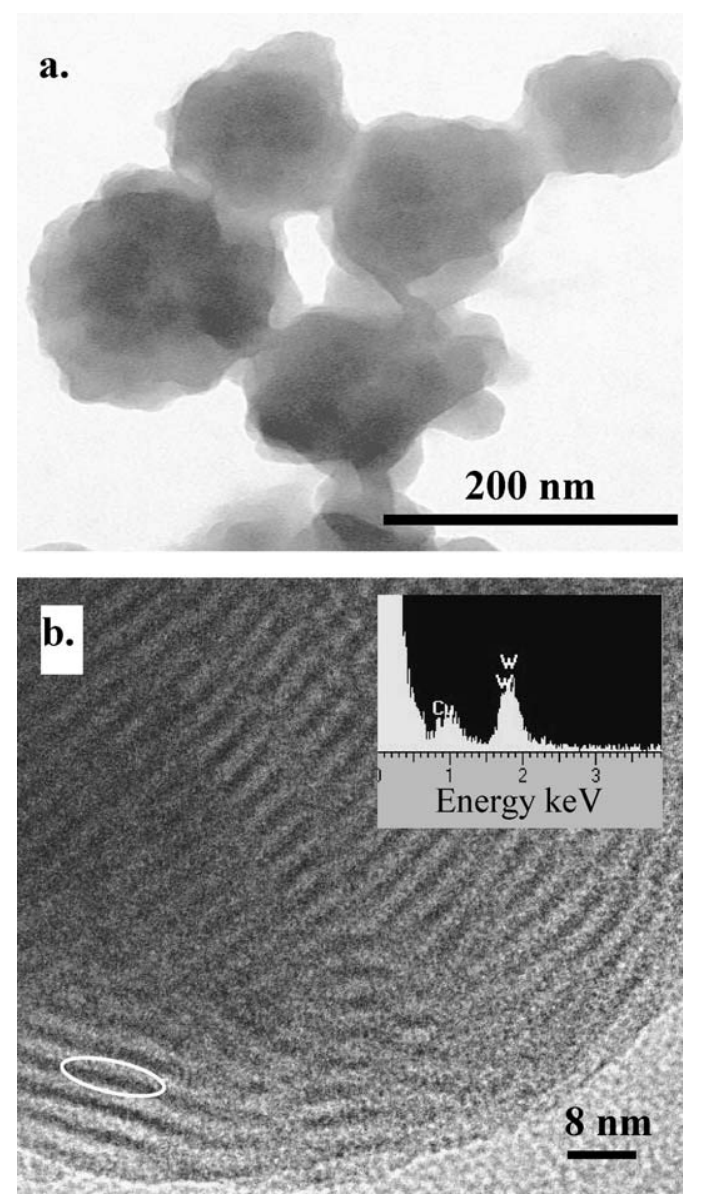

Fig. 3 (a) Wide area TEM image and (b) high resolution image of lamella structure of MDP-POM. Inset shows EDAX on highlighted region. 
benzyl-alcohol ${ }^{18}$ or alkylamine structure directing agents, ${ }^{19}$ however we believe this is the first report of such a self assembled, lamella hybrid material.

The nitrogen adsorption-desorption isotherm of MDP-POM (Fig. 4) is type IV with an H2 hysteresis loop; the shape of the isotherm suggests a slit shaped pore structure. Analysis of the pore sizes by the BJH method from the adsorption isotherm reveals a broad, mesoporous distribution (Fig. 4 inset) centred between 3-4 nm, consistent with the interlayer spacing observed by TEM. Related structures are reported by Tiemann et al. ${ }^{15}$ in MDP-derived porous aluminium phosphates.

DRIFT spectra of MDP and MDP-POM are shown in Fig. 5. Alkyl chain vibrations $v_{\mathrm{CH}}$ at $2850-2920$ and $\delta_{\mathrm{CH}} 1470 \mathrm{~cm}^{-1}$ can

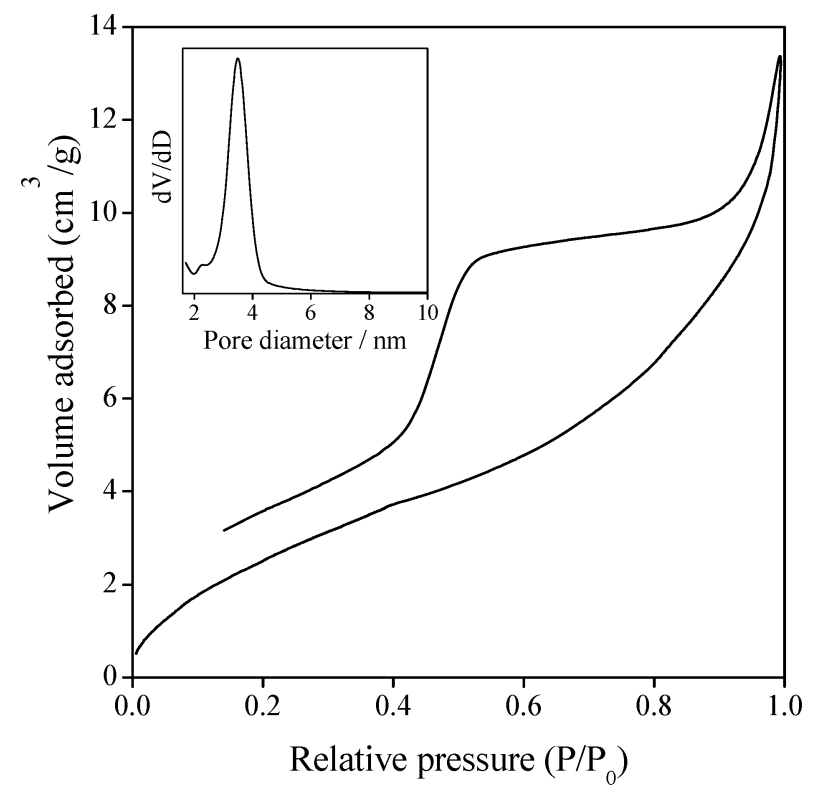

Fig. 4 Porosimetry of MDP-POM.

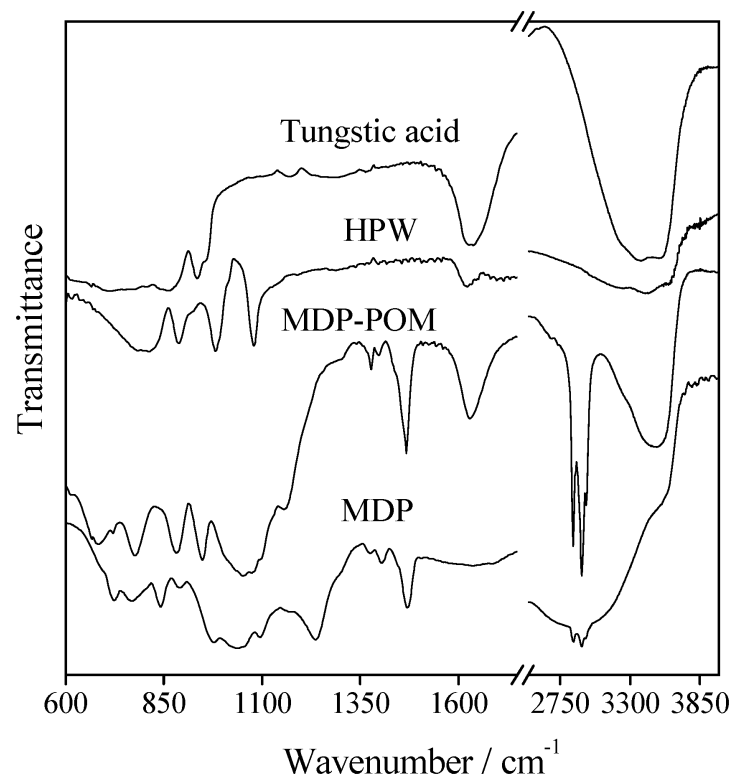

Fig. 5 Comparison of DRIFT spectra of MDP, MDP-POM and reference HPW and tungstic acid samples. be observed in all surfactant containing materials. The presence of $-\mathrm{OH}$ bending and stretching vibrations at $1620 \mathrm{~cm}^{-1}$ and 3510 $\mathrm{cm}^{-1}$ in the MDP-POM composite also indicates it is not hydrophobic, in contrast to the MDP starting material. The $v(\mathrm{P}-\mathrm{O})$, $v(\mathrm{P}-\mathrm{O}-\mathrm{R})$ and $v(\mathrm{P}-\mathrm{O}-\mathrm{C})$ modes are also visible between 900 $1500 \mathrm{~cm}^{-1}$. The peak pattern in this latter region differs between the MDP-POM and parent MDP, evidencing $\mathrm{P}-\mathrm{O}-\mathrm{W}$ interactions. The IR absorption bands of $\mathrm{H}_{3} \mathrm{PW}_{12} \mathrm{O}_{40}$ arising from the $v(\mathrm{P}-\mathrm{O}), v\left(\mathrm{~W}=\mathrm{O}_{\mathrm{t}}\right) v\left(\mathrm{~W}-\mathrm{O}_{\mathrm{b}}-\mathrm{W}\right)$ and $v\left(\mathrm{~W}-\mathrm{O}_{\mathrm{c}}-\mathrm{W}\right)$ stretches lie at $1080 \mathrm{~cm}^{-1}, 980 \mathrm{~cm}^{-1}, 890 \mathrm{~cm}^{-1}$ and $800 \mathrm{~cm}^{-1}$, respectively. ${ }^{20}$ These are close to, but not a perfect match for, the bands observed for MDP-POM, which exhibits modes at 1056, 946, 890 and $770 \mathrm{~cm}^{-1}$, suggesting the local tungsten environment within the hybrid is similar, but not identical, to that of Keggin-type phosophotungstic acid. The IR spectrum of lacunary $\mathrm{PW}_{9} \mathrm{O}_{34}{ }^{9-}\left(\mathrm{PW}_{9}\right)$ structures are reported to have characteristic bands at $1060 \mathrm{~cm}^{-1}, 930 \mathrm{~cm}^{-1}, 820 \mathrm{~cm}^{-1}$ and $760 \mathrm{~cm}^{-1},{ }^{21}$ which are in close agreement with those observed in MDPPOM. The shift between HPW and lacunary species is attributed to decreased local $\mathrm{T}_{\mathrm{d}}$ symmetry of the $\mathrm{PO}_{4}$ group in the lacunary arrangement following removal of a triad of corner-sharing $\mathrm{WO}_{6}$ groups. The resulting short $\mathrm{P}-\mathrm{O}$ bonds distort the $\mathrm{WO}_{6}$ octahedral symmetry, resulting in distinct $\mathrm{W}-\mathrm{O}$ bonds: the shortest $\mathrm{W}-\mathrm{O}$ bond $\left(980 \mathrm{~cm}^{-1}\right)$ is associated with the fragment of the anion that has undergone the triad, while the weakest $\mathrm{W}-\mathrm{O}$ bond is located at $818-746 \mathrm{~cm}^{-1}$.

Raman spectra are very sensitive to differences in polyoxotungtate environments and provide further insight into the hybrid material. Spectra of the MDP and MDP-POM are shown in Fig. 6. Sharp and intense Raman bands due to $\mathrm{C}-\mathrm{H}$ stretching vibrations appear around $2800-3000 \mathrm{~cm}^{-1}$ for both parent and composite. The vibrations due to $\mathrm{P}-\mathrm{O}, \mathrm{P}-\mathrm{OH}$ and $\mathrm{P}-\mathrm{O}-\mathrm{C}$ stretching modes fall between $900 \mathrm{~cm}^{-1}$ to $1500 \mathrm{~cm}^{-1} \cdot{ }^{22}$ Compared with pure MDP, new features emerge in the MDP-POM at 870 and $960 \mathrm{~cm}^{-1}$ in the correct region for symmetric $\mathrm{W}-\mathrm{O}-\mathrm{W}$

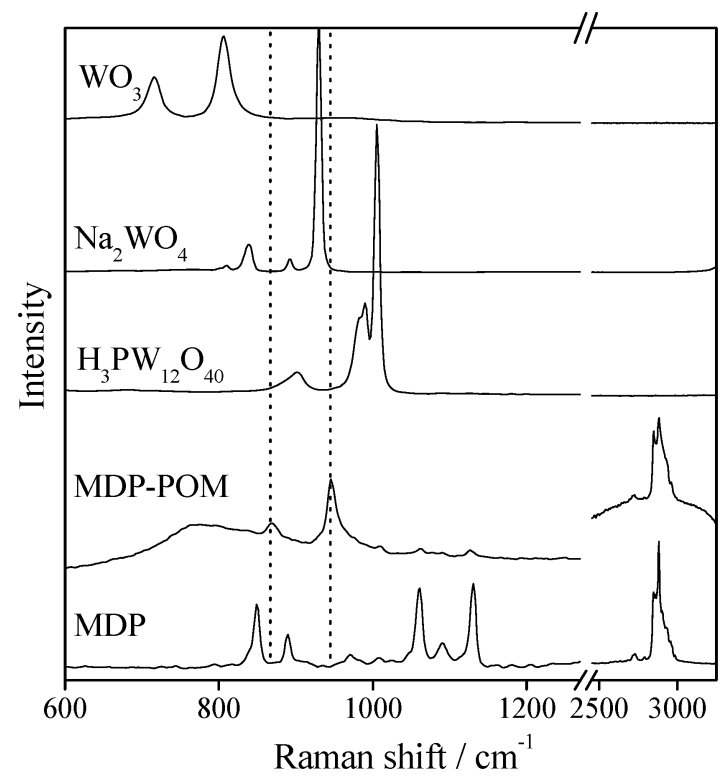

Fig. 6 Raman spectra of MDP, MDP-POM and reference HPW and tungstate samples. 
and terminal W-O vibrations, respectively. ${ }^{23}$ The two other small Raman peaks at $1015 \mathrm{~cm}^{-1}$ and $1060 \mathrm{~cm}^{-1}$ are assigned to $\mathrm{P}-\mathrm{O}$ stretching modes. Reference $\mathrm{Na}_{2} \mathrm{WO}_{4}$ and $\mathrm{WO}_{3}$ exhibit strong bands at $835\left(\nu_{\mathrm{as}} \mathrm{WO}_{4}{ }^{2-}\right)$ and $930\left(\nu_{\mathrm{S}} \mathrm{WO}_{4}{ }^{2-}\right) \mathrm{cm}^{-1}$, and $712(\delta \mathrm{W}-\mathrm{O})$ and $802 \mathrm{~cm}^{-1}(\nu \mathrm{W}-\mathrm{O})$, respectively. ${ }^{24}$ None of these correspond to the bands observed for MDP-POM, which therefore does not contain any bulk tungstate species. Detailed Raman studies of $\mathrm{WO}_{3} / \mathrm{ZrO}_{2}$ reveal typical modes for dispersed tungstate species of around $1019 \mathrm{~cm}^{-1}$ for terminal $\mathrm{W}=\mathrm{O}_{\text {sym }}$ of mono and poly tungstates, or 808 and $720 \mathrm{~cm}^{-1}$ for crystalline $\mathrm{WO}_{3}$, which tends to dominate at high loadings. ${ }^{25}$ In turn, bulk HPW exhibits Raman bands at 897, 980, 989 and 1005 $\mathrm{cm}^{-1}$ for $\nu_{\mathrm{as}}(\mathrm{W}-\mathrm{O}-\mathrm{W}), \nu_{\mathrm{as}}\left(\mathrm{W}-\mathrm{O}_{\mathrm{t}}\right), \nu_{\mathrm{as}}\left(\mathrm{W}-\mathrm{O}_{\mathrm{t}}\right)$ and $\nu_{\mathrm{s}}\left(\mathrm{W}=\mathrm{O}_{\mathrm{t}}\right)$, respectively, ${ }^{26}$ which again do not correlate with those for the hybrid MDP-POM. We recently showed that Keggin-like clusters constructed on zirconium phosphate supports yield similar spectral features ( 978 and $995 \mathrm{~cm}^{-1}$ ) to those of our new hybrid. ${ }^{27}$ Removal of a $\mathrm{WO}_{6}$ octahedra from a Keggin unit is reported to result in the appearance of new bands at 992 and $818-746 \mathrm{~cm}^{-1}$, akin to that for MDP-POM. ${ }^{23}$

Corresponding ${ }^{31} \mathrm{P}$ MAS NMR spectra are shown in Fig. 7. MDP shows a single sharp peak at $-3.7 \mathrm{ppm}$ assignable to $\mathrm{CH}_{3}\left(\mathrm{CH}_{2}\right)_{11} \mathrm{H}_{2} \mathrm{PO}_{4}$, while the hybrid material MDP-POM shows two broad peaks centred at $-3.5 \mathrm{ppm}$ and $-4.2 \mathrm{ppm}$ suggesting the presence of two MDP coordination environments. The ${ }^{31} \mathrm{P}$ NMR peak is expected to shift downfield with increased number of bulky cations, and our observed chemical shifts are indicative of phosphates with three bridging oxygens (here $\mathrm{P}-\mathrm{O}-\mathrm{W})$ and one terminal oxygen $(\mathrm{P}-\mathrm{O}-\mathrm{R}){ }^{28}{ }^{2}$ The ${ }^{31} \mathrm{P}$ chemical shift of lacunary Keggin structures decreases with cluster size: $\left[\mathrm{PW}_{12} \mathrm{O}_{40}\right]^{3-}\left(\mathrm{PW}_{12}\right), \mathrm{PW}_{11} \mathrm{O}_{39}{ }^{7-}\left(\mathrm{PW}_{11}\right)$ and $\mathrm{PW}_{9}$ lacunary clusters exhibit shifts of $-15,-11$ and $-4.8 \mathrm{ppm},{ }^{13}$ respectively. Our observed ${ }^{31} \mathrm{P}$ MAS NMR peak at $-4.2 \mathrm{ppm}$ is thus consistent with the formation of $\mathrm{PW}_{9}$ lacunary clusters, during our synthesis. Since elemental analysis reveals a $2: 1 \mathrm{~W}: \mathrm{P}$ ratio in the composite, and lacunary Keggin species are typically capped with cations, we propose the MDP surfactant caps Keggin-like

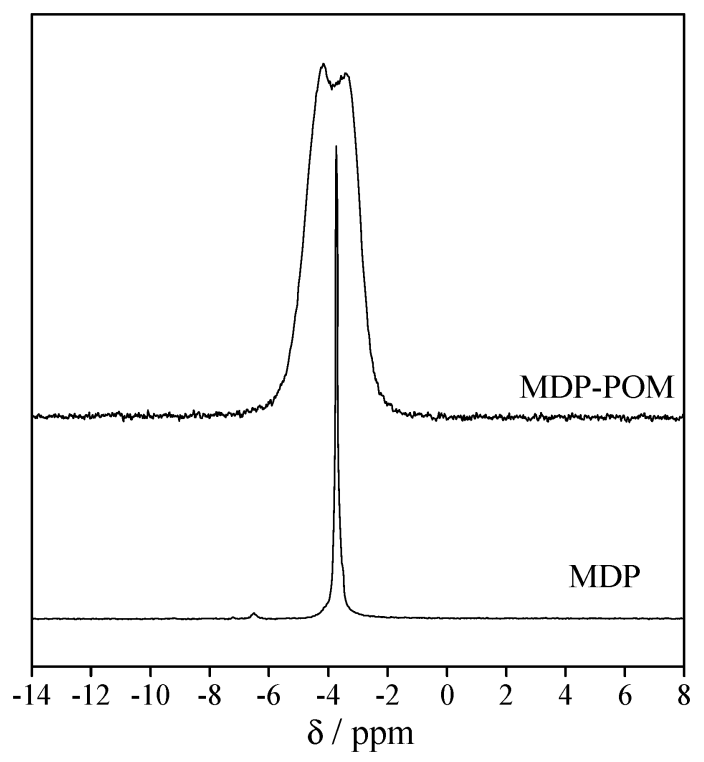

Fig. $7{ }^{31}$ P MAS NMR of MDP and MDP-POM samples.

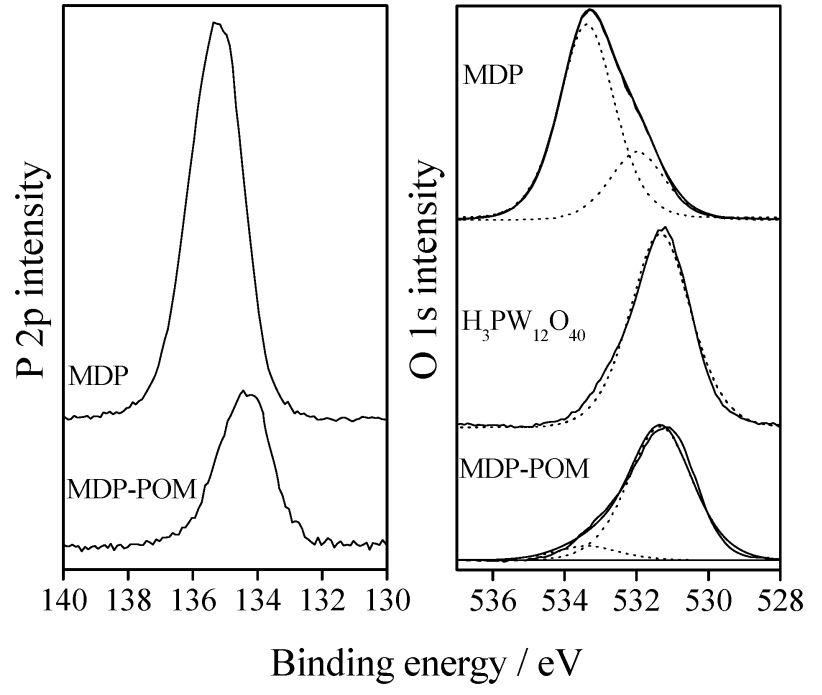

Fig. 8 P 2p and O 1s XP spectra of MDP and MDP-POM.

clusters with missing $\mathrm{WO}_{6}$ units and is responsible for the second ${ }^{31} \mathrm{P}$ environment.

Further evidence for a direct interaction between the head group of MDP and tungsten cages is provided from $\mathrm{P} 2 \mathrm{p}$ and $\mathrm{O}$ 1s XP spectra, shown in Fig. 8. The P 2 $\mathrm{p}_{3 / 2}$ transition lies at $135 \mathrm{eV}$ in MDP, consistent with that of an organophosphate species. Following reaction with sodium tungstate this peak shifts to lower binding energy. This reflects increased electron density on the $\mathrm{P}$ centre, as expected upon exchange of $\mathrm{OH}$ by $\mathrm{OW}$ neighbours. The $\mathrm{O} 1 \mathrm{~s}$ spectrum of MDP reveals two components at 533.4 and $531.9 \mathrm{eV}$ in a $3: 1$ ratio, arising from the $\mathrm{P}-\mathrm{OH}(\mathrm{R})$ and $\mathrm{P}=\mathrm{O}$ environments. Following reaction with $\mathrm{Na}_{2} \mathrm{WO}_{4}$ a new $\mathrm{O} 1 \mathrm{~s}$ state appears at $531.4 \mathrm{eV}$, matching the oxygen environment observed in reference $\mathrm{H}_{3} \mathrm{PW}_{12} \mathrm{O}_{40}$ clusters.

Interpreting these observations requires consideration of the tungstate species formed upon changing the $\mathrm{pH}$ of an aqueous $\mathrm{Na}_{2} \mathrm{WO}_{4} \cdot 2 \mathrm{H}_{2} \mathrm{O}$ solution. Scheme 1 shows the evolution of stable isopolytungstate anions as a function of $\mathrm{pH}$.

When a phosphorus source is introduced to solutions of both $\mathrm{Na}_{2} \mathrm{WO}_{4}(\mathrm{pH} 9.5)$ and the paratungstate ( $\mathrm{pH} 5-7$ ), reaction proceeds to form a series of unsaturated heteropoly compounds including $\mathrm{PW}_{9}$ and $\mathrm{PW}_{11}$ with the end product being a mixture of $\mathrm{PW}_{12}$ and $\left[\mathrm{P}_{2} \mathrm{~W}_{21} \mathrm{O}_{71}\right]^{6-}$ heteropoly ions. ${ }^{29}$ When a $\mathrm{pH}$ of $\sim 2$ is employed, formation of $\mathrm{PW}_{12}$ clusters dominates and is the normal pathway employed to synthesise heteropoly acids in the presence of $\mathrm{H}_{3} \mathrm{PO}_{4}$. In the present synthesis, using MDP in

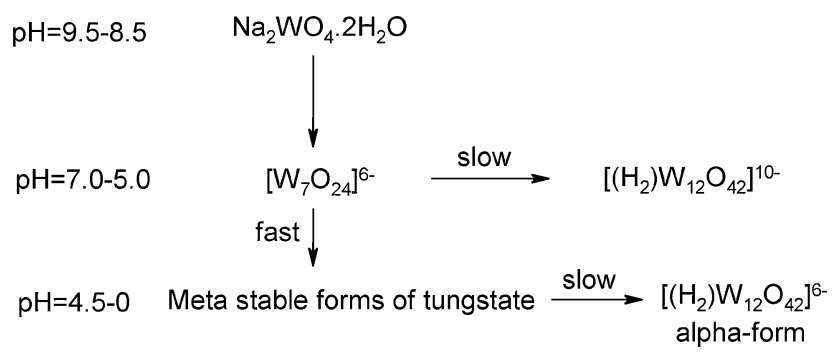

Scheme 1 Condensation of $\mathrm{Na}_{2} \mathrm{WO}_{4} \cdot 2 \mathrm{H}_{2} \mathrm{O}$ at different $\mathrm{pH}$. 
place of phosphoric acid, the formation of a lacunary $\mathrm{PW}_{9}$ cage around the $\mathrm{R}-\mathrm{OP}=\mathrm{O}(\mathrm{OH})_{2}$ headgroup was expected due to the steric constraints of the alkyl chain. However, this is inconsistent with the phosphorus-rich stoichiometry $(2: 1 \mathrm{~W}: \mathrm{P}$ ratio) suggesting the formation of a more complex structure. Such a composition could result from formation of monophosphate tungsten bronzes, ${ }^{30}$ which have the general formula $\left(\mathrm{PO}_{2}\right)_{4}$ $\left(\mathrm{WO}_{3}\right)_{2 m}$ where $2<m<14$. These contain slabs of cornersharing $\mathrm{WO}_{6}$ octahedra separated by $\mathrm{PO}_{4}$ units. Our elemental analysis suggests formation of a $\left(\mathrm{PO}_{2}\right)_{4}\left(\mathrm{WO}_{3}\right)_{8}$ a hybrid composite, which crystallises in a $\mathrm{P} 22_{1} 2_{1} 2_{1}$ unit cell $^{31}$ (Scheme $2 \mathrm{a}$ ). In our compound the MDP headgroup appears to coordinate to $3 \mathrm{WO}_{6}$ units bridging the top and bottom layers of the lamella. However, this structure would only yield a layer thickness of $\sim 0.5 \mathrm{~nm}$,
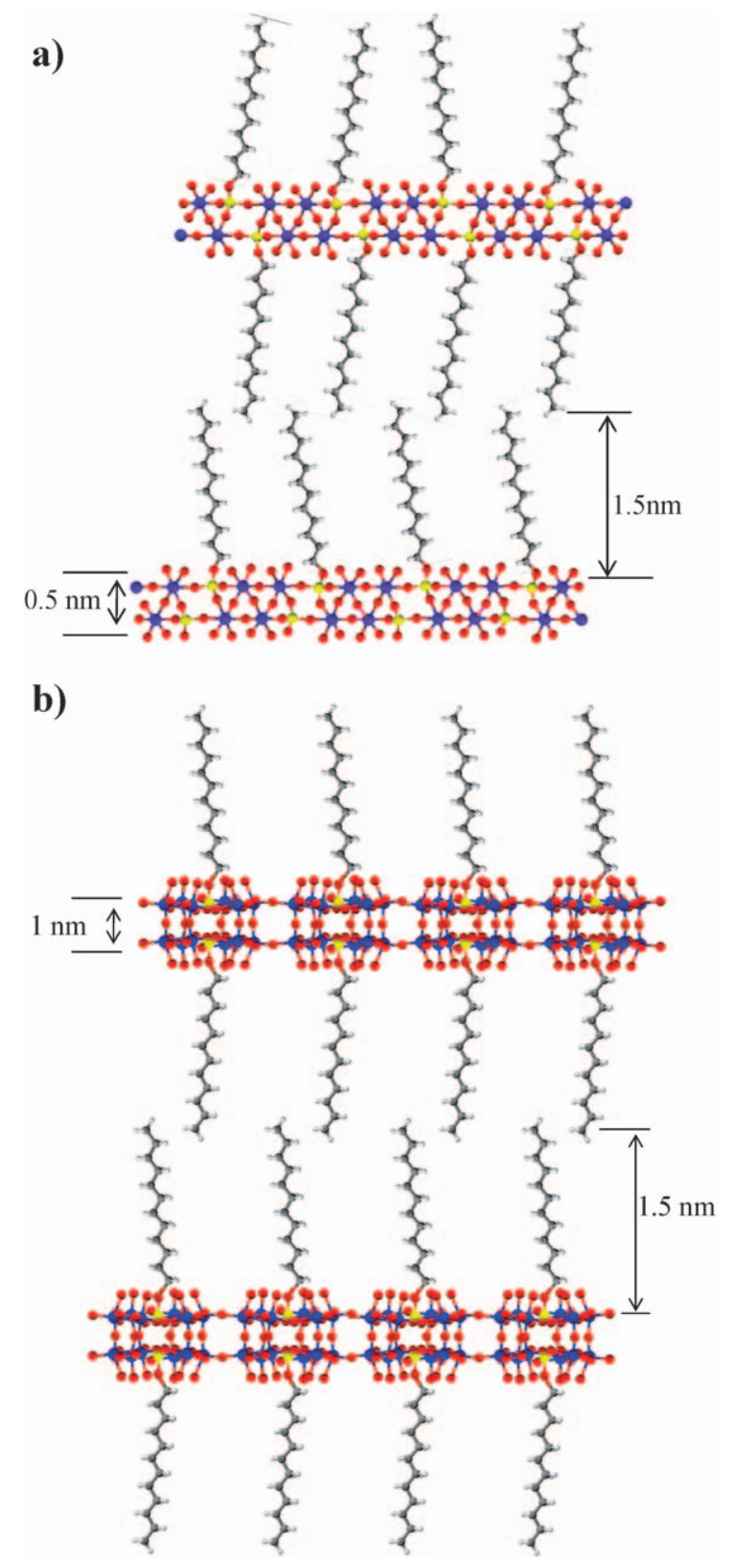

Scheme 2 Proposed structures for lamella MDP-POM (a) phosophotungstate bronze (b) lacunary Keggin based structures. inconsistent with TEM which shows the tungstate layer is twice this thickness. We thus posulate MDP promotes condensation of a $\mathrm{PW}_{6}$ bilayer to form a belt of capped lacunary clusters as observed for $\mathrm{P}_{2} \mathrm{~W}_{15} \mathrm{M}_{3} \mathrm{O}_{62}$ (Scheme $2 \mathrm{~b}$ ). ${ }^{32}$

The formation of similar lamella structures containing capped double-octahedral $\mathrm{W}-\mathrm{O}$ layers has also been observed following alkylamine templating of $\mathrm{H}_{2} \mathrm{~W}_{2} \mathrm{O}_{7} \cdot x \mathrm{H}_{2} \mathrm{O}$ clusters. ${ }^{19}$ In our case the presence of the alkyl chain from MDP sterically blocks capping of the cluster by a tunsgtate triad and creation of $\mathrm{W}_{9}$ units. We propose that an additional $4 \mathrm{MDP}$ units (not shown in Scheme 2) cap the unsaturated $\mathrm{W}-\mathrm{O}$ bonds to give an overall $\mathrm{P}_{6} \mathrm{~W}_{12}$ cluster. Note this model generates two distinct phosphorus environments as seen by ${ }^{31} \mathrm{P}$ MAS-NMR.

In summary, we have prepared the first phospho-tungstate organic-inorganic hybrid material which shows a highly ordered layered structure, which we believe is comprised of lacunary Keggin units. We believe these materials could find application in areas such as catalysis and photochemistry, which are presently under investigation in our laboratory.

\section{Conclusions}

Nano sized lamellar organic-inorganic hybrid have been successfully prepared by reacting mono dodecyl phosphate with sodium tungstate under conditions employed for syntheisis of Keggin structures. Phosphate head groups of MDP have reactive oxygen atoms that interact strongly with tungsten oxide forming a lacunary POM. Small angle XRD following grafting of $\mathrm{WO}_{3}$ groups reveals a ordered lamella structure upon templating with the MDP amphiphiles. This is in good agreement with TEM which shows a lamella spacing of $\sim 3.2 \mathrm{~nm}$. FTIR, Raman and ${ }^{31} \mathrm{P}$ MAS NMR suggest the formation of a lacunary Keggin species based on a $\mathrm{PW}_{9}$ structure. Taking account of the elemental analysis we propose a bilayer $\mathrm{P}_{6} \mathrm{~W}_{12}$ structure forms which is capped by additional MDP in the interlayer region.

\section{Acknowledgements}

K. N. Rao thanks the Royal Society, London, UK for the award of a Royal Society Indian Fellowship. Support for the York JEOL Nanocentre by the University of York, JEOL, Yorkshire Forward and the European Union (European Regional Development Fund) is also gratefully acknowledged.

\section{References}

1 Functional Hybrid Materials, ed. P. Gomez-Romero and C. Sanchez, Wiley-VCH, Weinheim, 2003.

2 M. A. Hickner, H. Ghassemi, Y. S. Kim, B. R. Einsla and J. E. McGrath, Chem. Rev., 2004, 104, 4587.

3 M. Gratzel, Nature, 2001, 414, 338.

4 Y. S. Kim, M. A. Hickner, L. Dong, B. S. Pivovar and J. E. McGrath, J. Membr. Sci., 2004, 243, 317.

5 T. Okuhara, N. Mizuno and M. Misono, Adv. Catal., 1996, 41, 113. 6 Polyoxometalates: From Platonic Solids to Anti-Retroviral Activity, ed. A. Muller and M. T. Pope, Kluwer Academic, Dordrecht, 1994.

7 Z. Kang, E. Wang, M. Jiang and S. Lian, Nanotechnology, 2004, 15, 55 .

8 A. Muller, E. Krickemeyer, J. Meyer, H. Bogge, F. Peters, W. Plass, E. Diemann, S. Dillinger, F. Nonnenbruch, M. Randerath and C. Menke, Angew. Chem., Int. Ed. Engl., 1995, 34, 2122.

9 D. G. Kurth, P. Lehmann, D. Volkmer, H. Colfen, M. J. Koop, A. Muller and A. D. Chesne, Chem.-Eur. J., 2000, 6, 385. 
10 S. Polarz, B. Smarsly and M. Antonietti, ChemPhysChem, 2001, 2 .

11 T. Zhang, C. Spitz, M. Antonietti and C. F. J. Faul, Chem.-Eur. J., 2005, 11, 1001

12 G. Maayan, R. Popovitz-Biro and R. Neumann, J. Am. Chem. Soc., 2006, 128, 4968.

13 A. Stein, M. Fendorf, T. P. Jarvie, K. T. Mueller, A. J. Benesi and T. E. Mallouk, Chem. Mater., 1995, 7, 304.

14 A. Taguchi, T. Abe and M. Iwamoto, Microporous Mesoporous Mater., 1998, 21, 387.

15 M. Fröba and M Tiemann, Chem. Mater., 1998, 10, 3475.

16 Y. Wu and S. Bose, Langmuir, 2005, 21, 3232.

17 M. S. Wong and J. Y. Ying, Chem. Mater., 1998, 10, 2067.

18 J. Polleux, M. Antonietti and M. Niederberger, J. Mater. Chem., 2006, 40,3969.

19 D. Chen and Y. Sugahara, Chem. Mater., 2007, 19, 1808

20 M. Misono, Catal. Rev. Sci. Eng., 1987, 29, 269.

21 R. Contnat, Can. J. Chem., 1987, 65, 568.

22 E. J. Baran and I. L. Botto, J. Solid State Chem., 1990, 89, 144.
23 C. I. Carmen, G. E. Maria, L. B. Irma and M. Giuliano, Mater. Chem. Phys., 2004, 87, 264.

24 S. Loridant, C. Feche, N. Essayem and F. Figueras, J. Phys. Chem. B, $2005,109,5631$

25 D. G. Barton, M. Shtein, R. D. Wilson, S. L. Soledand and E. Iglesia, J. Phys. Chem. B, 1999, 103, 630

26 A. J. Bridgeman, Chem. Phys., 2003, 287, 55.

27 K. Narasimharao, A. Sridhar, A. F. Lee, S. J. Tavener, N. A. Young and K. Wilson, Green Chem., 2006, 8, 790.

28 W. H. Knoth, P. J. Domaille and R. D. Farlee, Organometallics, 1985, 4,62 .

29 C. M. Tourne, G. F. Tourne and T. J. R. Weakley, J. Chem. Soc., Dalton Trans., 1986, 2237.

30 M. Dusek, J. Lüdecke and S. van Smaalen, J. Mater. Chem., 2002, 12, 1408.

31 J. P. Giroult, M. Goreaud, P. H. Labbe and B. Raveau, Acta Crystallogr., Sect. B: Struct. Crystallogr. Cryst. Chem., 1981, 37, 2139.

32 R. G. Finke, M. W. Droege and P. J. Domaille, Inorg. Chem., 1987, 26, 3886 . 